\title{
Recurrent abdominal wall dermatofibrosarcoma protuberans in a child: a challenging reconstruction
}

\author{
Karthik C Vallam', Monica Bhagat ${ }^{1}$, Vinay Shankhdhar² and Sajid S Qureshi ${ }^{\text {1* }}$
}

\begin{abstract}
Introduction: Dermatofibrosarcoma protuberans is an uncommon low-grade soft tissue sarcoma with a high potential for recurrence as it has irregular finger like extensions.

Case description: We report a case of a large, recurrent dermatofibrosarcoma protuberans in a child involving the anterior abdominal wall, which posed a challenge for reconstruction. Peritoneum sparing full thickness resection of the anterior abdominal wall, meshplasty and a free anterolateral thigh flap was performed for reconstruction of the defect.
\end{abstract}

Discussion and evaluation: Large composite defect, involving more than half of the anterior abdominal wall, necessitate a free flap reconstruction. Although these reconstructions are technically challenging in children, they are the only option available.

Conclusion: Complete surgical excision is essential for DFSP of the abdominal wall, which may result in large challenging defects. Free flaps remain the only option in this scenario and hence it is essential to have expertise for microvascular flap reconstruction.

Keywords: Dermatofibrosarcoma protuberans, Children, Abdominal wall, Surgery, Reconstruction, Anterolateral thigh flap

\section{Background}

Dermatofibrosarcoma protuberans (DFSP) is an uncommon, low grade soft tissue sarcoma of fibroblast origin. Surgical excision with negative resection margins is crucial to prevent recurrences (Bichakjian et al. 2014). The resultant soft tissue and skin defect often require reconstruction. Anterior abdominal wall defects are technically challenging to reconstruct especially in children since large donor areas are not available due to the small frame of children.

We present our experience in managing a child with recurrent DFSP of the anterior abdominal wall.

\footnotetext{
*Correspondence: sajidshafiques@hotmail.com

${ }^{1}$ Division of Pediatric Surgical Oncology, Department of Surgical Oncology, Tata Memorial Centre, Ernest Borges Road, Parel,

Bombay 400012, India

Full list of author information is available at the end of the article
}

\section{Case description}

A 10-year old boy presented with a recurrent abdominal wall tumor. The patient had an incomplete surgery 3 years earlier and had undergone two surgeries subsequently for recurrent swellings. There was neither history of trauma or any family history of similar swellings. Clinically the mass was $8 \times 6 \mathrm{~cm}$ involving the skin and subcutaneous tissue with an $11 \mathrm{~cm}$ horizontal scar with prominent hatch marks and a separate drain site scar (Figure 1). Computerised tomography scan revealed a hypodense, ovoid mass measuring $3.8 \times 7.9 \times 8.4 \mathrm{~cm}$ infiltrating the rectus sheath with no obvious intra-abdominal extension (Figure 2).

Core needle biopsy was suggestive of DFSP. Surgical excision was planned with a wide margin of $2 \mathrm{~cm}$ and excising the entire rectus sheath (both anterior and posterior layers along with the muscles). The skin with the linear scar, hatch marks and the drain site scar were

\section{Springer}

(C) 2015 Vallam et al. This article is distributed under the terms of the Creative Commons Attribution 4.0 International License (http://creativecommons.org/licenses/by/4.0/), which permits unrestricted use, distribution, and reproduction in any medium, provided you give appropriate credit to the original author(s) and the source, provide a link to the Creative Commons license, and indicate if changes were made. 


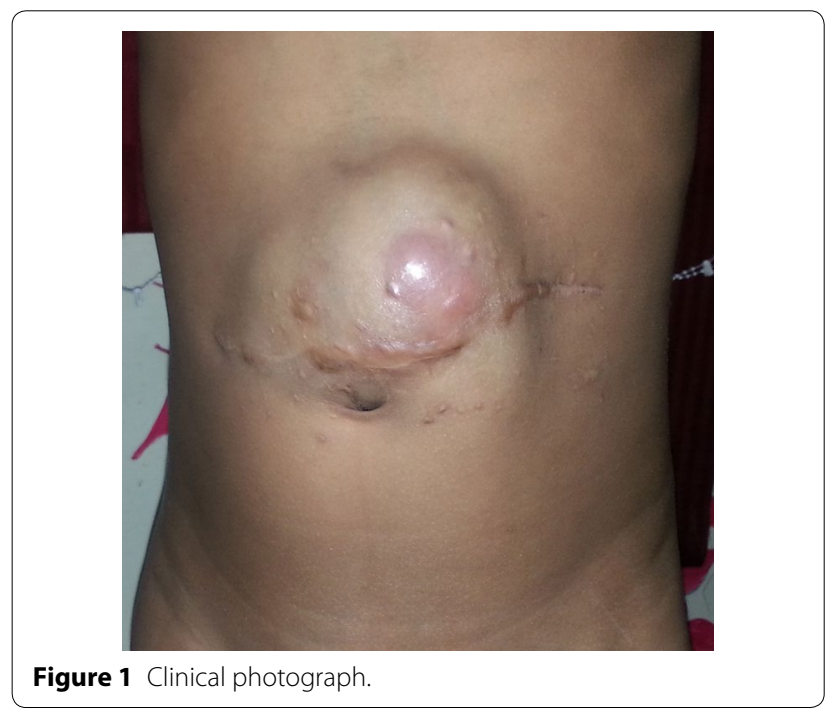

included in the resection (Figure 3). Since there was no intra-abdominal extension, the peritoneum was left intact except at one place where the tumor was abutting it (Figures 4,5). Due to the sparse underlying omentum, placement of intraperitoneal mesh was deferred. The peritoneum was mobilized all around until the lateral abdominal wall and a primary closure of peritoneum was achieved (Figure 6). A pre-peritoneal VYPRO ${ }^{\circ}$ mesh was placed and anchored to the peritoneum (Figure 7). A free anterolateral thigh flap was harvested from the thigh and microvascular anastamosis was performed between the flap vasculature (cutaneous perforators of the descending branch of the lateral femoral circumflex vessels) and the deep inferior epigastric vessels (Figure 8). The deep fascia of the flap was sutured to the rectus sheath and skin approximated (Figure 9).
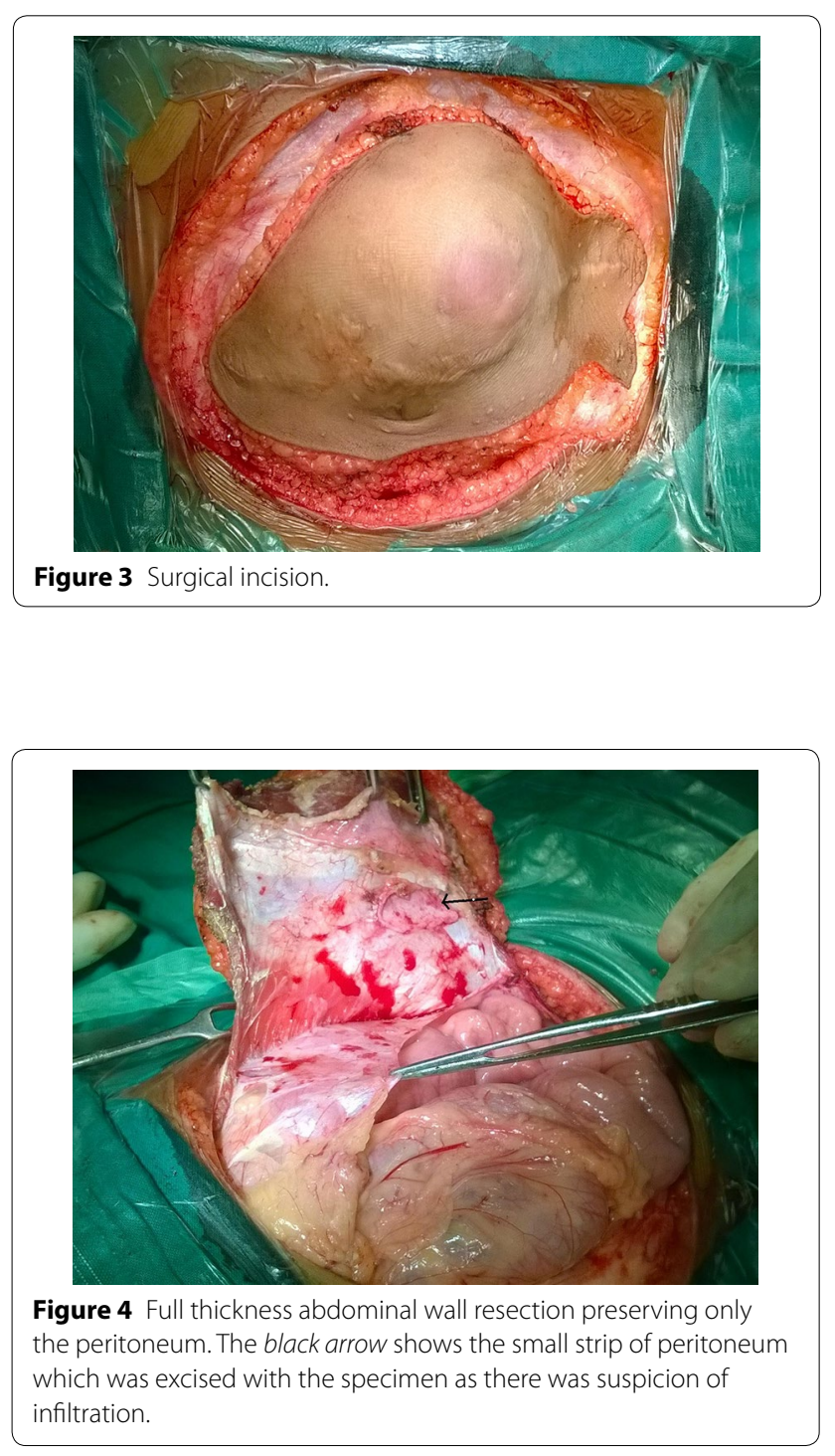

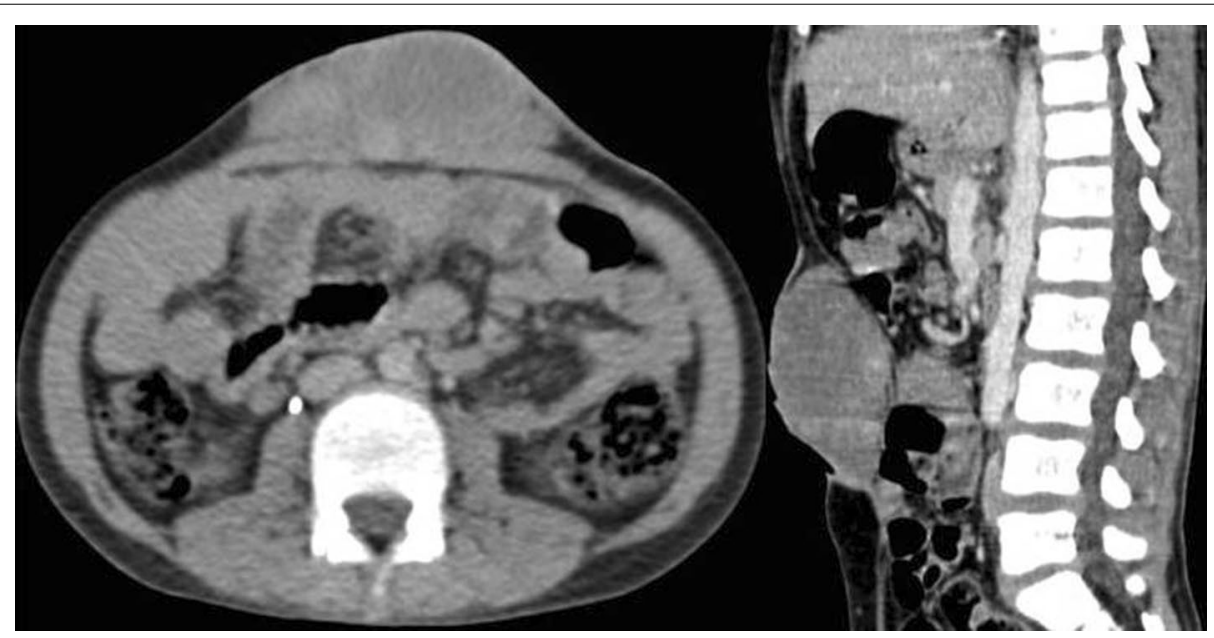

Figure 2 Computerized tomography images (axial and sagital) showing the lesion in the anterior abdominal wall. 


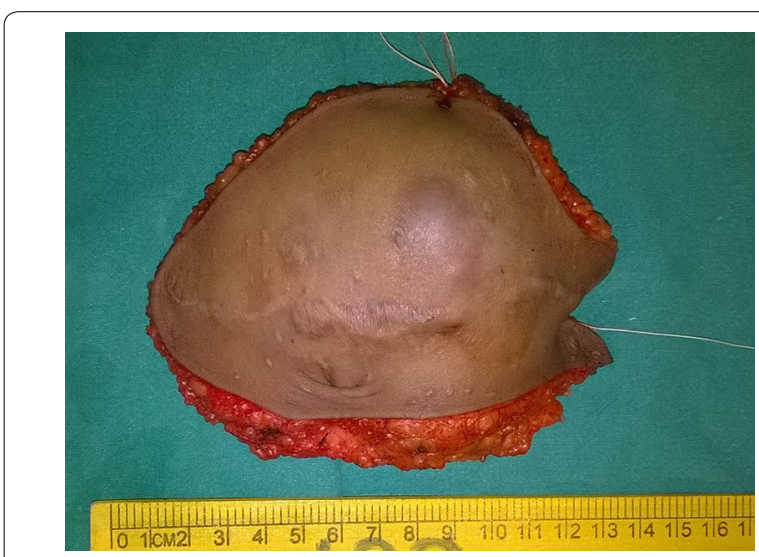

Figure 5 Resected specimen.

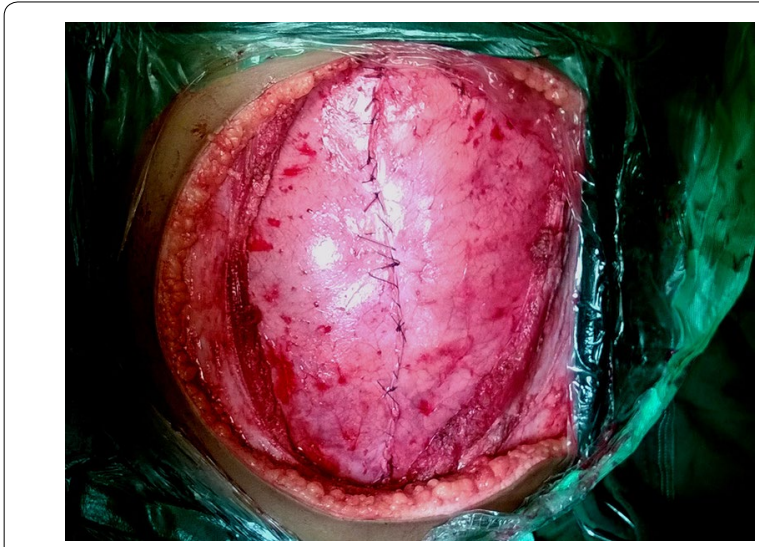

Figure 6 Primary closure of peritoneum.

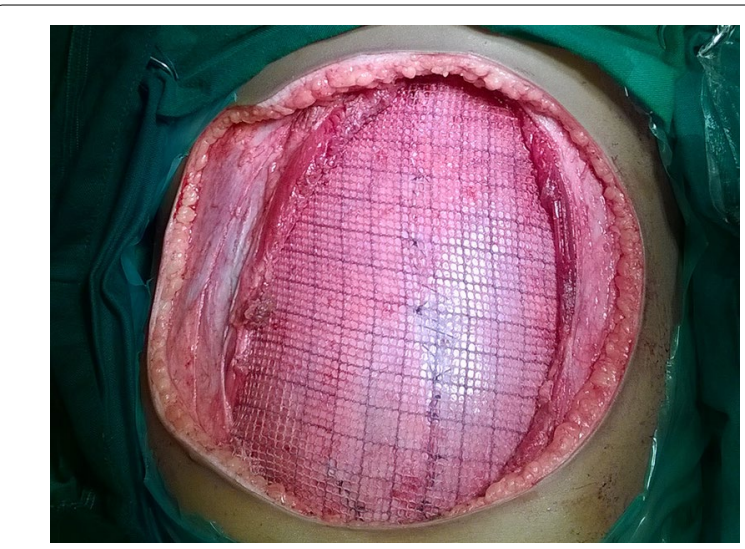

Figure 7 Pre-peritoneal mesh placement.

The patient had an uneventful recovery and was discharged from the hospital on the eighth postoperative day. All surgical resection margins were negative. The closest margin was $2 \mathrm{~mm}$ microscopically although

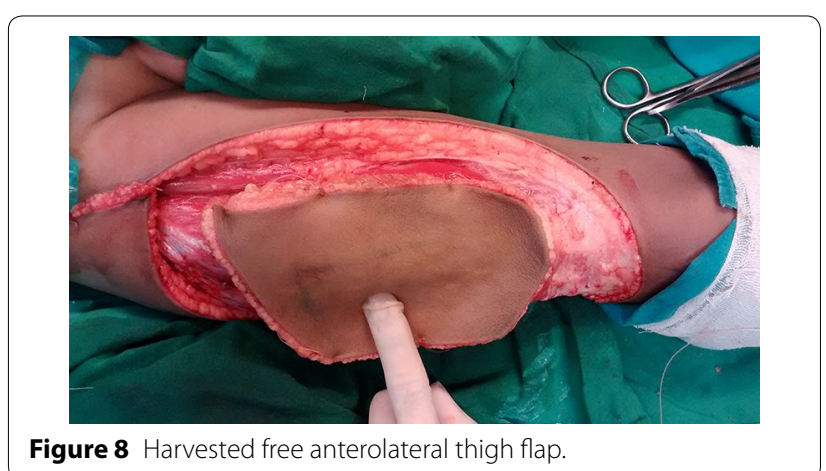

Figure 8 Harvested free anterolateral thigh flap.

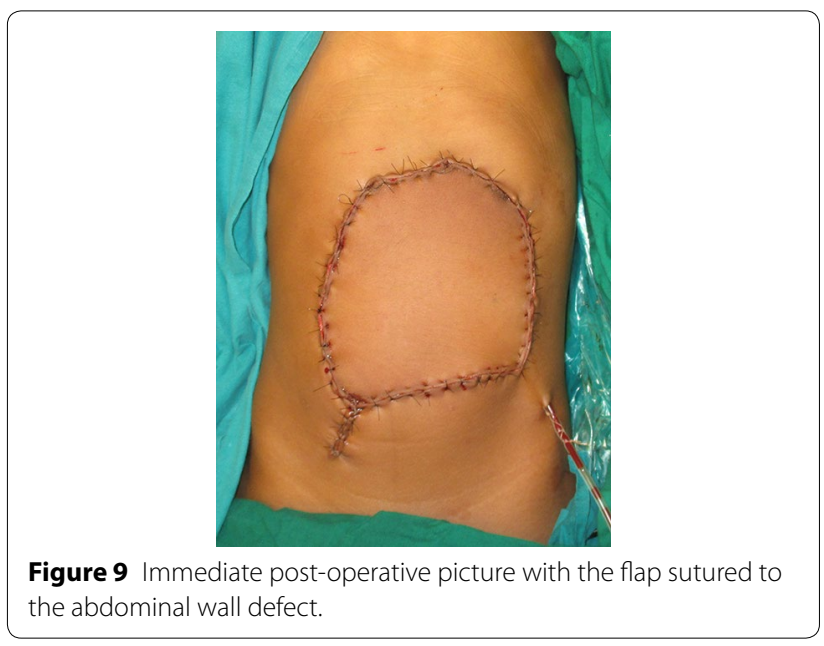

grossly it was $12 \mathrm{~mm}$ away. The patient received postoperative radiotherapy $(5,040 \mathrm{cGy} / 28 \#)$. At first follow up after three months the flap is well healed and the patient is disease free.

\section{Discussion}

DFSP is a locally aggressive tumor with a high potential for recurrence as it has irregular finger like extensions (Bichakjian et al. 2014). The closest margin in our case was grossly $12 \mathrm{~mm}$ away from the tumour, however, on microscopic examination the tumor was extending till $2 \mathrm{~mm}$ from the cut margin indicating microscopic spread beyond grossly visualized disease which is difficult to assess intra-operatively. Due to this penchant of DFSP for microscopic extension beyond the gross confines and prior recurrences a wide excision with $2 \mathrm{~cm}$ margin was planned.

Kawaguchi et al. (2004) had suggested a thick fascial barrier (like the posterior layer of the rectus sheath) to be equivalent to a $3 \mathrm{~cm}$ cuff of soft tissue. Applying this concept, the entire posterior rectus sheath was excised along with the peritoneum only where the tumour had 
Table 1 Available options for reconstruction of large abdominal wall defects

\begin{tabular}{|c|c|c|}
\hline & Pros & Cons \\
\hline \multirow[t]{2}{*}{ Latissimus dorsi flap } & Constant vascular anatomy with long pedicle and large diameter & Significant motor deficit at donor site \\
\hline & $\begin{array}{l}\text { Donor defect can be closed primarily if skin paddle required is } \\
\text { small-better cosmesis }\end{array}$ & Available skin paddle is small though muscle bulk is good \\
\hline \multirow[t]{2}{*}{ Anterolateral thigh flap } & Long vascular pedicle with relatively large diameter & Donor site cosmesis is poor \\
\hline & Large skin paddle & \\
\hline \multirow[t]{2}{*}{ Tensor fascia lata flap } & Consistent, lengthy vascular pedicle & Donor site cosmesis is poor \\
\hline & No significant functional loss at donor site & Bulky flap \\
\hline
\end{tabular}

infiltrated focally. Preserving the peritoneum was crucial as the omentum was sparse and the bowel would have been exposed to the mesh. Intra-peritoneally placed meshes are prone to complications like extensive adhesions leading to chronic pain and increased chance of intestinal obstruction, sinus formation, infection, enterocolic fistula, etc. In addition, there is no conclusive evidence to suggest that the newer mesh like expanded polytetrafluoroethylene (ePTFE) or acellular dermal matrices are better than the basic polypropylene mesh (Ramakrishna and Lakshman 2013). As our patient had a large composite defect, involving more than half of the anterior abdominal wall, a free flap was the only feasible option. Free flaps that have been used for reconstruction of such defects are latissimus dorsi myocutaneous flap, the tensor fascia lata flap and the anterolateral thigh flap. The pros and cons of each of these flaps have been enlisted in Table 1 (Serafin 1995). Irrespective of the choice of flap, long term complications should be minimized as survival is very good in DFSP.

\section{Conclusion}

Complete surgical excision is essential for DFSP of the abdominal wall which may result in large challenging defects. Free flaps remain the only option in this scenario and hence it is essential to have expertise for microvascular flap reconstruction.

\footnotetext{
Author details

${ }^{1}$ Division of Pediatric Surgical Oncology, Department of Surgical Oncology, Tata Memorial Centre, Ernest Borges Road, Parel, Bombay 400012, India.

${ }^{2}$ Department of Plastic and Reconstructive Surgery, Tata Memorial Centre, Bombay, India.
}

\section{Authors' contributions}

SQ performed the surgical resection with the assistance of KCV and MB. VS performed the microvascular reconstruction. KCV drafted the manuscript with the assistance of MB. All authors were involved in review of literature. All authors read and approved the final manuscript.

\section{Acknowledgements}

We would like to thank Mr. Mehboob Shah for meticulous data collection and compilation.

\section{Compliance with ethical guideline}

\section{Competing interests}

The authors declare that they have no competing interests.

Received: 23 February 2015 Accepted: 29 June 2015

Published online: 08 July 2015

\section{References}

Bichakjian CK, Olencki T, Alam M, Anderso JS, Berg D, Bowen GM et al (2014) Dermatofibrosarcoma protuberans, version 1.2014. J Natl Compr Cancer Netw JNCCN 12:863-868

Kawaguchi N, Ahmed AR, Matsumoto S, Manabe J, Matsushita Y (2004) The concept of curative margin in surgery for bone and soft tissue sarcoma. Clin Orthop 419:165-172

Ramakrishna HK, Lakshman K (2013) Intra peritoneal polypropylene mesh and newer meshes in Ventral Hernia Repair: What EBM Says? Indian J Surg 75:346-351. doi:10.1007/s12262-012-0743-x

Serafin D (1995) Atlas of microsurgical composite tissue transplantation. Saunders, Philadelphia

\section{Submit your manuscript to a SpringerOpen ${ }^{\circ}$} journal and benefit from:

- Convenient online submission

- Rigorous peer review

- Immediate publication on acceptance

- Open access: articles freely available online

- High visibility within the field

- Retaining the copyright to your article

Submit your next manuscript at $>$ springeropen.com 